\title{
Determinação da rigidez de Pinus elliottii em diferentes teores de umidade por meio de ensaios mecânicos não destrutivos
}

\author{
Determination of stiffness of Pinus elliottii with different \\ moisture contents by non-destructive mechanical testing
}

\author{
Diego Henrique de Almeida1, Fabiane Salles Ferro², Felipe Hideyoshi Icimoto², \\ Saly Takeshita ${ }^{3}$, Karina Soares Modes ${ }^{4}$, Tiago Hendrigo de Almeida², \\ André Luis Christoforo ${ }^{5}$ e Francisco Antonio Rocco Lahr ${ }^{6}$
}

\begin{abstract}
Resumo
A madeira é um dos principais materiais utilizados na construção civil por causa da sua disponibilidade, grande resistência mecânica em relação ao seu baixo peso específico quando comparado a outros materiais e, também, pelo ponto de vista da sustentabilidade esse material se destaca. Para melhor utilização desse recurso natural em seus diversos seguimentos é importante o conhecimento de suas propriedades físicas e mecânicas. O objetivo do seguinte trabalho foi a determinação da rigidez de peças estruturais de madeira da espécie Pinus elliottii em diferentes teores de umidade utilizando os métodos de flexão estática e vibração transversal para determinação do módulo de elasticidade (MOE). Concluímos que os valores de MOE das amostras com teores de umidade a $12 \%$ não diferiram entre os dois métodos utilizados, porém, o mesmo não aconteceu com as amostras com teor de umidade igual a 54\%.
\end{abstract}

Palavras-chave: Vibração transversal, flexão estática, módulo de elasticidade, teor de umidade.

\begin{abstract}
Wood is a principal material used in construction because of its availability, high mechanical strength relative to its low density compared to other materials and also because of its sustainability. To best use this natural resource in various segments it is important to be aware of its physical and mechanical properties. Our goal was to determine the stiffness of structural lumber of Pinus elliottii with different moisture contents by using the methods for bending and transverse vibration to determine the modulus of elasticity (MOE). We conclude that MOE values of samples with moisture content equal to $12 \%$ did not differ between the two methods, however, the same did not happen with the samples with moisture content equal to $54 \%$.
\end{abstract}

Keywords: Transverse vibration, bending, modulus of elasticity, moisture content.

\section{INTRODUÇÃO}

Ao longo dos anos a madeira tem conquistado seu espaço na construção civil e destacando-se como um importante elemento estrutural, principalmente pelo desenvolvimento de pesquisas e avanço na tecnologia empregada em seu beneficiamento, utilização de agentes preservantes com maior qualidade e a vantagem de, também, utilizar espécies de reflorestamento como as dos gêneros Pinus, Eucalyptus e Corymbia (BERTOLINI, 2011).

De acordo com Carreira e Dias (2006) a utilização estrutural da madeira serrada oriunda de florestas plantadas apresenta, no Brasil, um considerável potencial para expansão, devido, prin-

${ }^{1}$ Professor do Departamento de Engenharias. Faculdade Pitágoras/Campus Poços de Caldas (MG). Avenida João Pinheiro, 1046 - 37701-386 - Poços de Caldas, MG, Brasil. E-mail: diegoestruturas@gmail.com.

${ }^{2}$ Doutorando(a) Ciências e Engenharia de Materiais. USP - Universidade de São Paulo / EESC - Escola de Engenharia de São Carlos. Avenida Trabalhador Sancarlense, 100 - 13566590 - São Carlos, SP, Brasil. E-mail: fsferro@usp.br; icimoto@usp.br; tiago@usp.br.

${ }^{3}$ Doutora em Recusros Florestais. USP - Universidade de São Paulo / ESALQ - Escola Superior de Agricultura "Luiz de Queiroz". Av. Pádua Dias, 11 - Caixa Postal 11 - 13419-900 - Piracicaba, SP, Brasil. E-mail: $\underline{\text { saly@usp.br. }}$

${ }^{4}$ Professora Adjunta do Departamento de Engenharia Florestal. UFSC - Universidade Federal de Santa Catarina. Km 3, Ulysses Gaboardy, 89520-000 - Curitibanos, SC, Brasil. E-mail: modes@usp.br.

${ }^{5}$ Professor Adjunto do Departamento de Engenharia Civil. UFSCar - Universidade Federal de São Carlos. Rodovia Washington Luís, km 235 - SP-310 - 36307352 - São Carlos, SP, Brasil. E-mail: christoforoal@yahoo.com.

${ }^{6}$ Professor Titular do Departamento de Engenharia de Estruturas. USP - Universidade de São Paulo / EESC - Escola de Engenharia de São Carlos. Av. Trabalhador Sãocarlense, 400 - 13566590 - São Carlos, SP. E-mail: frocco@sc.usp.br

Sci. For., Piracicaba, v. 44, n. 110, p. 303-309, jun. 2016 DOI: dx.doi.org/10.18671/scifor.v44n110.03 
Almeida et al. - Determinação da rigidez de Pinus elliottii em diferentes

teores de umidade por meio de ensaios mecânicos não destrutivos

cipalmente, à redução da oferta de madeira tropical observada na atualidade. Como alternativa, o mercado se volta para o uso das madeiras oriundas de reflorestamentos, com destaque para o gênero Pinus.

Porém, a madeira é um material que apresenta grande variabilidade em sua estrutura, e, consequentemente em suas propriedades físicas e mecânicas, e sua aplicação está condicionada ao conhecimento destas características. Para a utilização da madeira em projetos de construção civil o conhecimento em propriedades como resistência e rigidez do material é fundamental. Diante destes fatos, a Associação Brasileira de Normas Técnicas em seu documento ABNT (1997) fornece as diretrizes para realização de ensaios laboratoriais para a determinação dessas propriedades.

Tanto as propriedades físicas quanto as mecânicas são influenciadas diretamente pelo teor de umidade da madeira, no entanto, alterações nestas propriedades restringem-se ao intervalo entre o Ponto de Saturação das Fibras (PSF) e o estado seco (HILDEBRAND, 1970). Este PSF é definido como o teor de umidade a partir do qual, mesmo que a madeira ganhe massa devido ao ganho de umidade, o seu volume saturado permanece constante (KOLLMANN; CÔTÉ, 1968; GALVÃO; JANKOWSKY, 1985). O ponto de saturação das fibras, em geral, corresponde a um teor de umidade entre 20\% e 30\% A ABNT (1997) adota como referência o teor de umidade igual a 25\%. Em relação aos valores de resistência e rigidez, a madeira apresenta variações pouco significativas para teores de umidade acima de 20\% (LOGSDON; CALIL JR., 2002).

As propriedades mecânicas são entendidas como "respostas às solicitações" impostas ao material e são divididas em propriedades mecânicas de resistência (como por exemplo: resistência à compressão paralela às fibras e resistência à tração paralela às fibras) e de rigidez (como por exemplos: módulo de elasticidade em ensaios de compressão paralela às fibras e módulo de elasticidade em ensaios de tração paralela às fibras) (ALMEIDA et al., 2012; ALMEIDA et al., 2013). Para determinação dessas propriedades podem ser empregados métodos destrutivos e métodos não destrutivos.

Os ensaios não destrutivos apresentam algumas vantagens em relação aos destrutivos, tais como: os ensaios são realizados diretamente nas peças que serão colocadas em serviço e, geralmente, em todas as peças de um lote.

Dentre os métodos não destrutivos para classificação mecânica de peças estruturais de madeira pode ser mencionada a classificação por flexão estática e por vibração transversal, com determinação do módulo de elasticidade (MOE) pelos dois métodos (MORALES, 2006; CANDIAN, 2007; CARREIRA; CANDIAN, 2008).

Na classificação mecânica por flexão estática, aplica-se uma força conhecida sobre a peça flexionando a mesma em relação ao seu eixo de menor inércia. O módulo de elasticidade pode ser determinado pela seguinte expressão.

$$
\mathrm{MOE}=\frac{\mathrm{P} \cdot \mathrm{L}^{3}}{48 \cdot f_{\mathrm{max}} \cdot \mathrm{I}}
$$

Em que: $\mathrm{MOE}=$ módulo de elasticidade em ensaio de flexão estática $(\mathrm{MPa}) ; \mathrm{P}=$ força aplicada no centro do vão $(\mathrm{N}) ; \mathrm{L}=$ comprimento do vão entre os apoios $(\mathrm{mm}) ; f_{\text {máx }}=$ flecha máxima obtida pela imposição da força $(\mathrm{mm}) ; \mathrm{I}=$ momento de inércia da peça $\left(\mathrm{mm}^{4}\right)$.

A aptidão da madeira em resistir ao deslocamento imposto por uma força é expressa numericamente por meio do seu módulo de elasticidade. Para um mesmo e determinado nível de carregamento, uma peça de baixo módulo de elasticidade sofre uma maior deformação do que outra com módulo de elasticidade superior (ROCHA et al., 1988).

A avaliação mecânica não destrutiva utilizando o método da vibração transversal consiste em aplicar um impacto a uma peça de madeira bi-apoiada (sendo que em um dos apoios é instalado uma célula de carga), fazendo com que a mesma vibre na sua frequência natural até que a vibração cesse em função do amortecimento. A célula de carga capta a vibração da viga e transfere o sinal a um circuito condicionador, que amplifica e filtra a vibração. O sinal é enviado a um microcomputador que determina a frequência do sinal oscilante (Figura 1). Conhecendo-se as características dimensionais da peça e sua massa é determinado o módulo de elasticidade pelo método da vibração de acordo com a equação abaixo. 


$$
\mathrm{MOE}=\frac{f_{\mathrm{r}}^{2} \cdot \mathrm{m} \cdot \mathrm{L}^{3}}{2,46 \cdot \mathrm{g} \cdot \mathrm{I}}
$$

Em que: $f r$ = frequência de ressonância $(\mathrm{Hz}) ; \mathrm{m}=$ massa da peça estrutural de madeira $(\mathrm{kg}) ; \mathrm{g}=$ aceleração da gravidade (adota-se $9,8 \mathrm{~m} / \mathrm{s}^{2}$ ).

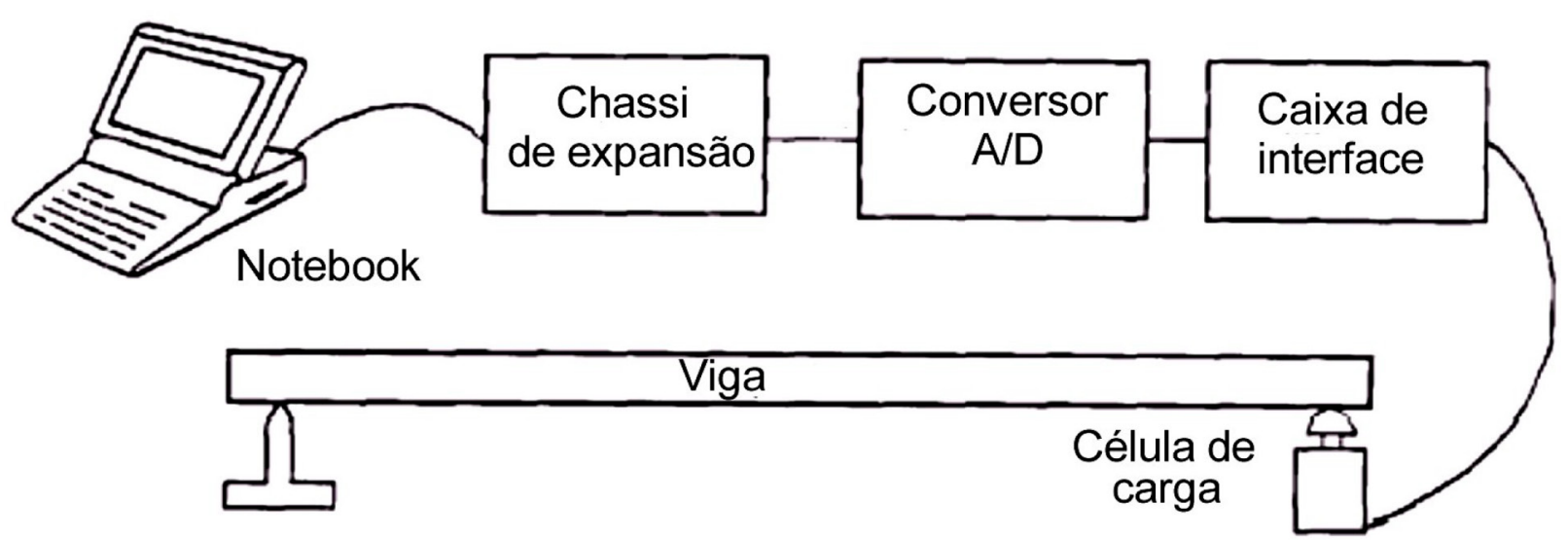

Figura 1. Esquema de um equipamento para determinação do MOE por vibração transversal. Fonte: CALIL NETO, 2011.

Figure 1. Scheme of equipment for determining the MOE by transverse vibration. Source: CALIL NETO, 2011.

O presente trabalho foi conduzido com objetivo de verificar a correlação existente entre os valores do módulo de elasticidade de peças de madeira de Pinus determinados pelo método de flexão estática e pelo ensaio de vibração transversal em peças de madeira com diferentes teores de umidade $(12$ e $54 \%)$.

\section{MATERIAL E MÉTODOS}

Para execução da presente pesquisa foram utilizadas 40 tábuas de madeira de Pinus elliottii, provenientes de árvores de floresta plantada na região de Itapetininga (interior de São Paulo), com idade entre 18 e 20 anos, dimensões de $2,5 \mathrm{~cm}$ e 3,5 cm de espessura, $15 \mathrm{~cm}$ de largura e $250 \mathrm{~cm}$ de comprimento. Das 40 peças selecionadas para a pesquisa, 20 apresentavam teor de umidade de $12 \%$ e 20 peças estavam com o teor de umidade de $54 \%$. Os teores de umidade foram determinados pelo método descrito no Anexo B da norma ABNT (1997).

Para realização dos ensaios foram medidas, utilizando um paquímetro de precisão $0,01 \mathrm{~mm}$, as dimensões da seção transversal e com um metro o comprimento das 40 peças selecionadas.

Os valores característicos do MOE para cada peça foram determinados por meio dos ensaios de flexão estática e de vibração transversal, ambos não destrutivos.

Com o intuito da verificação da equivalência estatística entre os valores de MOE determinados pelos dois métodos nos dois teores de umidade diferentes, utilizamos o intervalo de confiança da diferença entre médias, expresso a seguir.

$$
x_{m}-\frac{s_{m} \cdot t_{0}}{\sqrt{n}} \leq \mu \leq x_{m}+\frac{s_{m} \cdot t_{0}}{\sqrt{n}}
$$

Em que: $\mathrm{x}_{\mathrm{m}}=$ média aritmética amostral das diferenças; $\mathrm{s}_{\mathrm{m}}=$ desvio padrão amostral das diferenças; $\mathrm{n}=$ tamanho da amostra; $\mathrm{t}_{0}=$ valor tabelado pela distribuição $\mathrm{t}$ de Student com $\mathrm{n}-1$ graus de liberdade; $\mu$ = média populacional das diferenças.

\section{Método de Flexão Estática}

O ensaio de flexão estática foi conduzido com as extremidades das peças sobre apoios e no meio do vão livre $(240 \mathrm{~cm})$ colocadas duas diferentes forças $(20 \mathrm{~N} \mathrm{e} 40 \mathrm{~N} ; 30 \mathrm{~N} \mathrm{e} 60 \mathrm{~N} ; 50 \mathrm{~N}$ e $100 \mathrm{~N})$ e registrados, utilizando um relógio comparador de precisão $0,01 \mathrm{~mm}$ as flechas correspondentes às forças aplicadas no ponto central do meio das tábuas (Figura 2). A definição das forças utilizadas se deteve à capacidade do relógio comparador em registrar o deslocamento sofrido pela peça. 


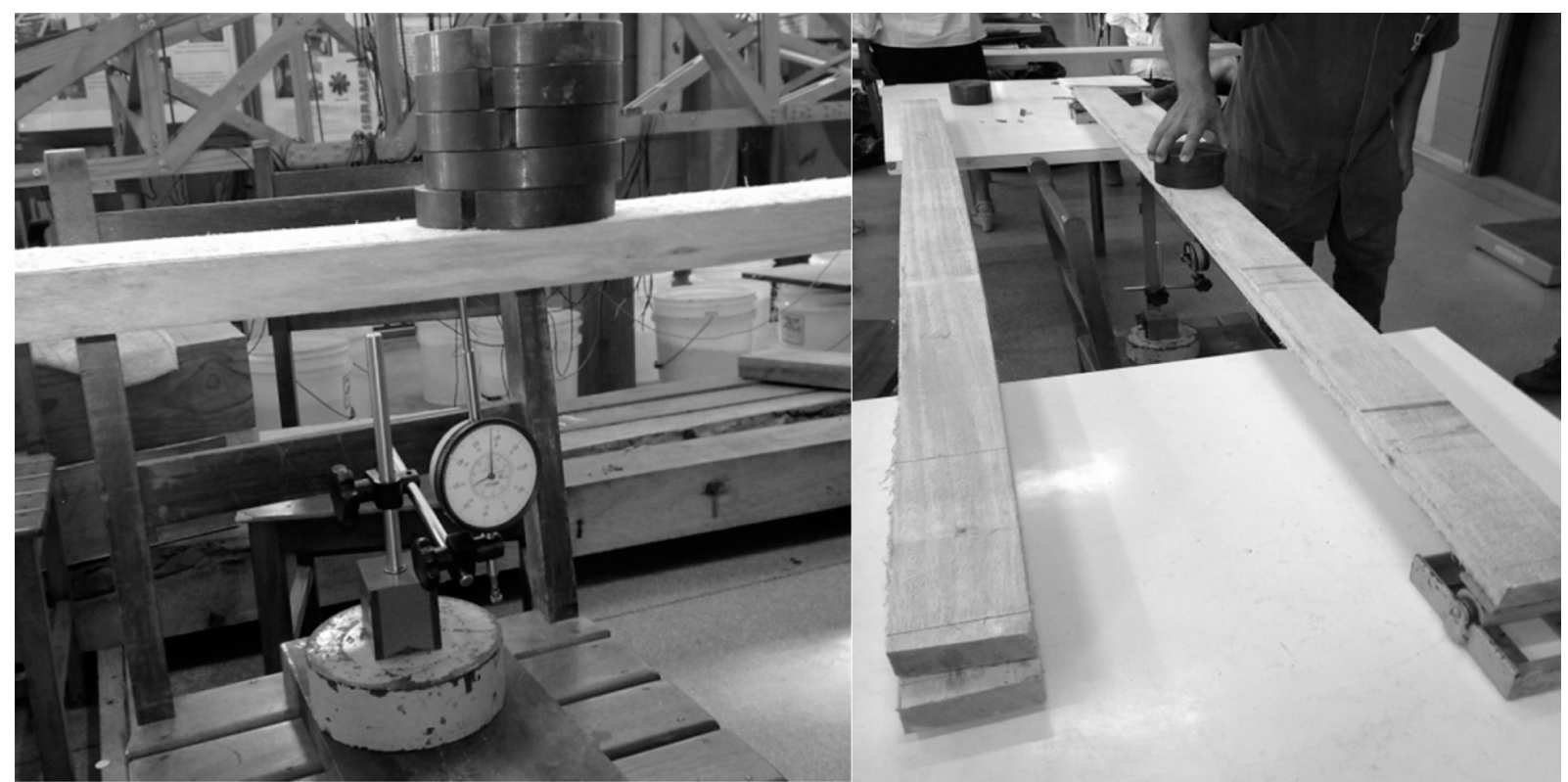

Figura 2. Ensaio de flexão estática.

Figure 2. Bending test.

\section{Método de Vibração Transversal}

As mesmas peças também foram submetidas ao ensaio de vibração transversal para determinação do MOE utilizando o equipamento Transverse Vibration E-Computer, modelo 340 da Metriguard (Figura 3).

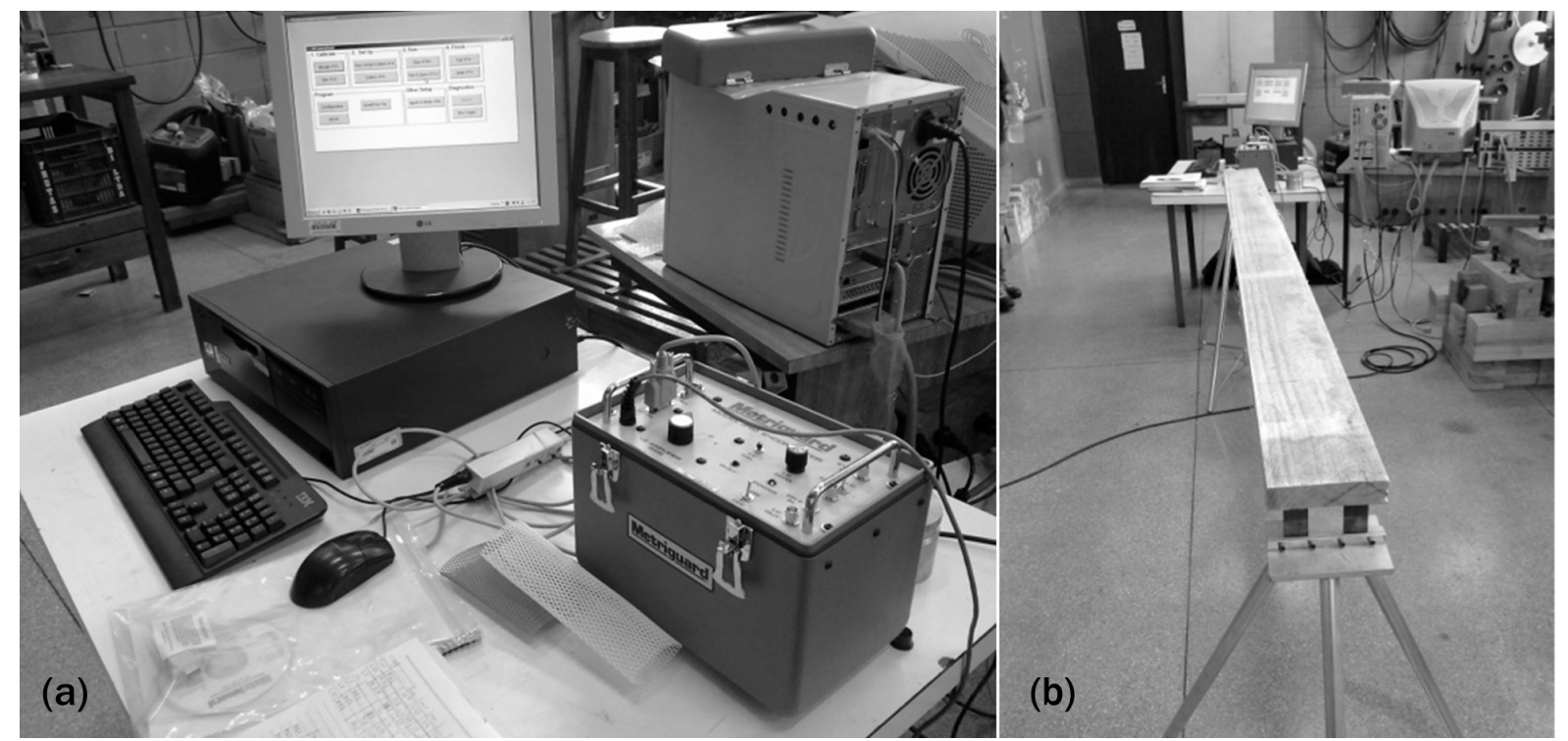

Figura 3. (a) Equipamento Transverse Vibration E-Computer; (b) Ensaio de vibração transversal. Figure 3. (a) Equipment Transverse Vibration E-Computer; (b) Test of transverse vibration.

Foi realizado um impacto no centro da peça bi-apoiada e a partir da frequência de vibração natural da peça, foram obtidos os valores da frequência de vibração. Os dados obtidos pelo equipamento foram enviados a um computador que realizou os cálculos e armazenou os dados e os resultados dos testes em um arquivo texto. Neste arquivo foi registrado para cada peça, o seu número, a seção transversal, frequência de vibração, a massa e o MOE.

\section{RESULTADOS}

Os valores determinados para os módulos de elasticidade de cada peça levando em consideração os métodos de flexão estática e por vibração transversal podem ser observados na Figura 4 para peças com teor de umidade $12 \%$ e na Figura 5 para as peças com 54\% de umidade. 


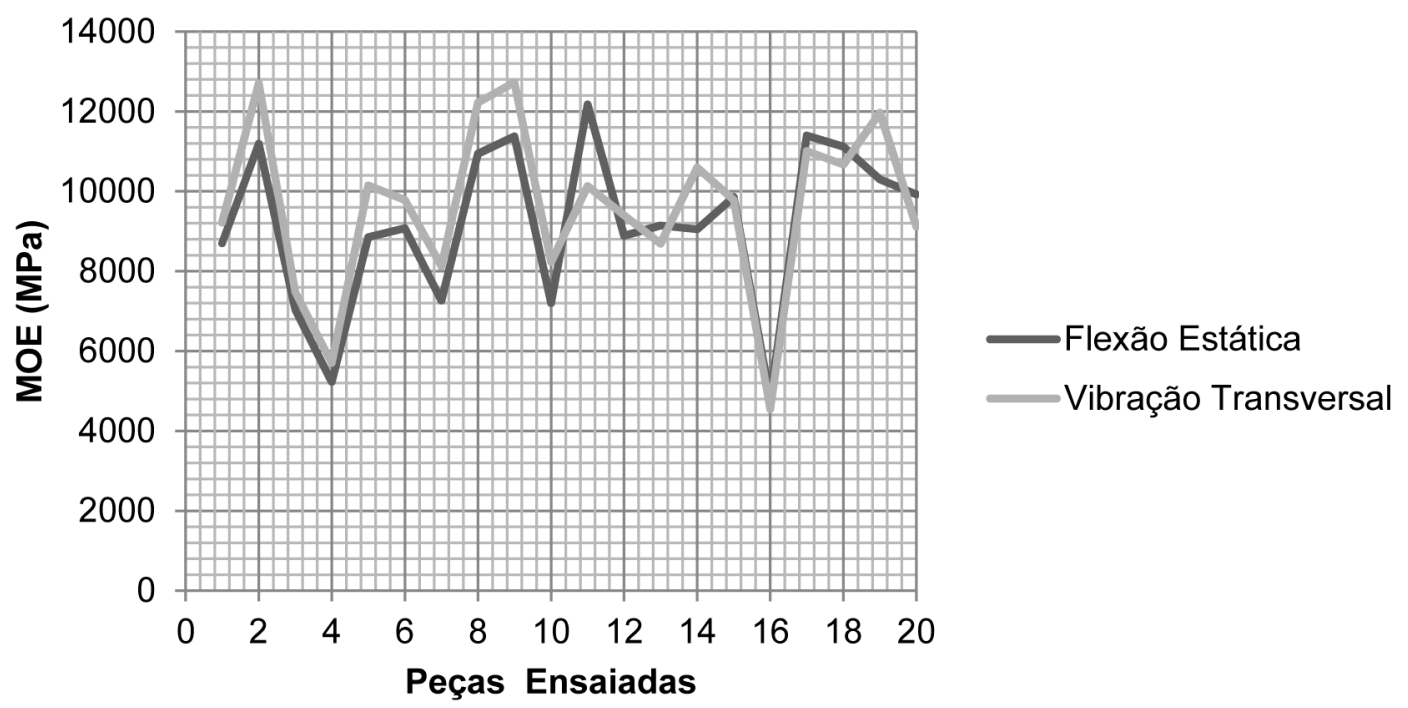

Figura 4. MOE das peças com teor de umidade $12 \%$ pelos métodos de flexão estática e vibração transversal. Figure 4. MOE of the samples with moisture content $12 \%$ by methods of bending and transverse vibration.

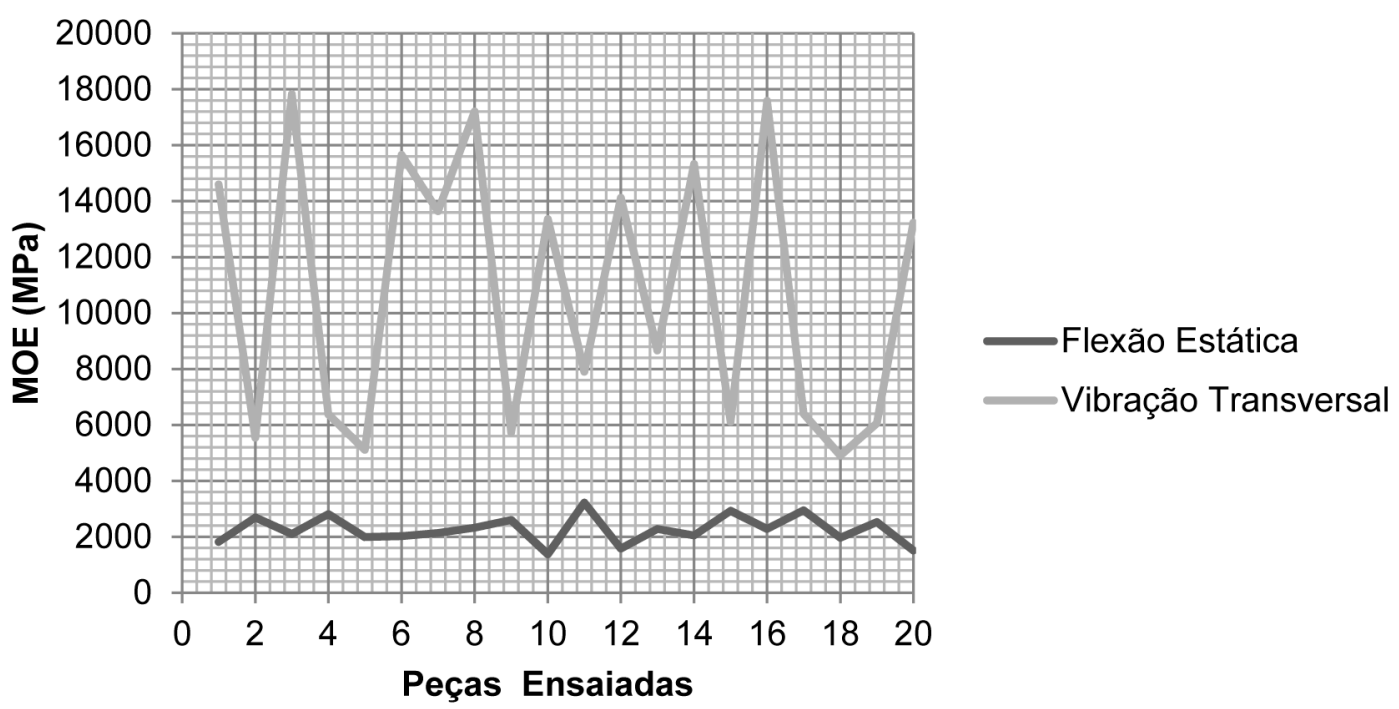

Figura 5. MOE das peças com teor de umidade 54\% pelos métodos de flexão estática e vibração transversal. Figure 5. MOE of the samples with $54 \%$ moisture content by methods of bending and transverse vibration.

\section{DISCUSSÃO}

As peças com teor de umidade de $12 \%$ tiveram valores de módulos de elasticidade muito próximos pelos dois métodos, porém, para as peças com 54\% de umidade os valores de módulo de elasticidade determinados pelo método da vibração transversal tiveram valores muito diferentes dos determinados pelo método da flexão estática. Não foram observadas diferenças significativas nos resultados entre as peças de $2,5 \mathrm{~cm} \mathrm{e} \mathrm{3,5} \mathrm{cm}$ de espessura.

Utilizando o intervalo de confiança de diferenças entre médias, pode-se constatar equivalência entre os valores de MOE em relação aos dois métodos utilizados para as peças com teor de umidade igual a $12 \%$. O mesmo não ocorreu para as peças saturadas com teor de umidade igual a $54 \%$. A massa de água contida na madeira saturada (54\%) interferiu na determinação do MOE, pela técnica da vibração transversal, por conta das diferentes densidades entre a água e a madeira.

Cossolino et al. (2011) realizaram ensaios para determinação do módulo de elasticidade do Pinus oocarpa utilizando ensaios de flexão estática e vibração transversal somente para peças com teores de umidade na faixa de $12 \%$ e não encontraram diferenças significativas nos valores de MOE determinados.

Após a realização dos ensaios determinaram-se os valores médios para os módulos de elasticidade das peças pelos métodos da flexão estática e da vibração transversal para os dois teores de umidade das peças. O valor médio determinado para os corpos-de-prova com teor de umidade igual a 
Almeida et al. - Determinação da rigidez de Pinus elliottii em diferentes

teores de umidade por meio de ensaios mecânicos não destrutivos

54\% foi maior para o método da vibração transversal em relação à flexão estática $79 \%$. A diferença entre os valores médios de MOE levando em conta as peças com $12 \%$ de umidade foi na ordem de 4,5\%. Targa et al. (2005) realizaram ensaios com peças dos gêneros Eucalyptus e Corymbia e encontraram diferença entre os valores médios determinados pelos métodos da vibração transversal e da flexão estática na ordem de $12 \%$ para as espécies Corymbia citriodora e Eucalyptus grandis, já para o Eucalyptus saligna a diferença foi igual a $28 \%$

Zangiácomo (2003) trabalhando com madeiras tropicais (com teor de umidade igual a 12\%) realizou ensaios para determinação do MOE pelos métodos da flexão estática e da vibração transversal em 81 peças de madeira e encontrou forte correlação, próxima de 1, entre os valores encontrados.

Calil Jr. e Miná (2003) determinaram os valores de módulo de elasticidade pelos métodos da vibração transversal e da flexão estática para a espécie norte-americana Southern Pine (Pinus do Sul), com umidade de $12 \%$ e encontraram uma forte correlação linear com coeficiente igual a 0,98.

\section{CONCLUSÕES}

O método da vibração transversal é uma boa alternativa para estimativa das propriedades mecânicas de peças estruturais de madeira, por causa do pequeno tempo para o ensaio e, também, por não ser destrutivo, porém, como determinado nesse trabalho, apenas para peças com teor de umidade próximo a $12 \%$.

Para peças com teores de umidade iguais a 12\% houve equivalência entre os valores encontrados para o MOE para ambos os métodos utilizados de acordo com o intervalo de confiança de diferença entre médias. Para as peças com teor de umidade igual a 54\% essa equivalência não foi possível e os valores encontrados para o MOE foram muito distintos.

\section{AGRADECIMENTOS}

A equipe agradece ao Laboratório de Madeiras e Estruturas de Madeiras (LaMEM) do Departamento de Estruturas (SET) da Escola de Engenharia de São Carlos (EESC) da Universidade de São Paulo (USP) pela possibilidade de realização desse trabalho.

\section{REFERÊNCIAS BIBLIOGRÁFICAS}

ABNT - ASSOCIAÇÃO BRASILEIRA DE NORMAS TÉCNICAS. NBR 7190: Projetos de estruturas de madeiras. Rio de Janeiro, 1997.

ALMEIDA, D. H.; MOLINA, J. C.; ALMEIDA, T. H.; CALIL JR., C. Determinação das propriedades mecânicas do Cumaru para construção de estruturas de madeira. In: CONGRESSO LATINOAMERICANO Y DEL CARIBE DE INGENIERÍA AGRÍCOLA, 10, 2012, Londrina. Anais... Londrina: ALIA, 2012. p. 1-4.

ALMEIDA, D. H.; SCALIANTE, R. M.; MACEDO, L. B.; MACEDO, A. N.; DIAS, A. A.; CHRISTOFORO, A. L.; CALIL JR., C. Caracterização completa da madeira da espécie amazônica Paricá (Schizolobium amazonicum HERB) em peças de dimensões estruturais, Revista Árvore, Viçosa, v. 37, n. 6, p. 1175-1181, 2013.

BERTOLINI, M. S. Emprego de resíduos de Pinnus sp tratado com preservante CCB na produção de chapas de partículas homogêneas utilizando resina poliuretana à base de mamona. 2011, 128 p. Dissertação (Mestrado em Ciência e Engenharia de Materiais), Universidade de São Paulo, São Carlos, 2011.

CALIL JR., C.; MINÁ, A. J. S. Vibração transversal: um método eficiente para a classificação de peças estruturais de madeira, Revista Brasileira de Engenharia Agrícola e Ambiental, v. 7, n. 2, p. 335-338, 2003.

CALIL NETO, C. Madeira laminada colada (MLC): controle de qualidade em combinações espécieadesivo-tratamento preservativo. 2011, 120 p. Dissertação (Mestrado em Ciência e Engenharia de Materiais), Universidade de São Paulo, São Carlos, 2011. 
CANDIAN, M. Estudo da classificação não destrutiva de peças serradas de espécies cultivadas no Brasil para uso em estruturas. 2007, 154 p. Dissertação (Mestrado em Construção Civil), Universidade Federal de São Carlos, São Carlos, 2007.

CARREIRA, M. R.; CANDIAN, M. Teste de um equipamento para classificação de peças estruturais de madeira pela técnica da vibração transversal, Semina: Ciências Exatas e da Terra, v. 29, n. 1, p. 3-14, 2008.

CARREIRA, M. R.; DIAS, A. A. Critérios para classificação visual de peças estruturais de Pinus sp, Cadernos de Engenharia de Estruturas, v. 8, n. 34, p. 17-43, 2006.

COSSOLINO, L. C.; PEREIRA, A. H. A.; ICIMOTO, F. H.; FERRO, F. S.; SEGUNDINHO, P. G. A.; CALIL JR., C. Avaliação da coerência entre três métodos de determinação do módulo de elasticidade da madeira de Pinus oocarpa. In: ENCONTRO REGIONAL EM MADEIRAS E ESTRUTURAS DE MADEIRAS, 3, 2011, São Carlos. Anais... São Carlos: IBRAMEM, 2011. p. 118-128.

GALVÃO, A. P. M.; JANKOWSKY, I. P. Secagem racional da madeira. São Paulo: Nobel, 1985. 112 p.

HILDEBRAND, R. Kiln drying of sawn timber. Berlin: Maschinenbau GmbH, 1970. 198 p.

KOLLMANN, F.; CÔTÉ, W. A. Principles of wood science and technology. Germany: Springer Verlag, 1968. $592 \mathrm{p}$.

LOGSDON, N. B.; CALIL JR., C. Influência da umidade nas propriedades de resistência e rigidez da madeira, Cadernos de Engenharia de Estruturas, v. 4, n. 18, p. 77-107, 2002.

MORALES, E. A. M. Técnicas de propagação de ondas na estimativa de propriedades mecânicas de painéis OSB. 2006, 209 p. Tese (Doutorado em Ciência e Engenharia de Materiais), Universidade de São Paulo, São Carlos, 2006.

ROCHA, J. S.; PAULA, E. V. C. M.; SIQUEIRA, M. L. Flexão estática em amostras pequenas livres de defeitos, Acta Amazônica, Manaus, v. 18, n. 1-2, p. 147-162, 1988.

TARGA, L. A.; BALLARIN, A. W.; BIAGGIONI, M. A. M. Avaliação do módulo de elasticidade da madeira com uso de método não-destrutivo de vibração transversal, Engenharia Agrícola, v. 25, n. 2, p. 291-299, 2005.

ZANGIÁCOMO, A. L. Emprego de espécies tropicais alternativas na produção de elementos estruturais de madeira laminada colada. 2003, 102 p. Dissertação (Mestrado em Engenharia de Estruturas), Universidade de São Paulo, São Carlos, 2003.

Recebido em 16/12/2014

Aceito para publicação em 19/10/2015

Sci. For., Piracicaba, v. 44, n. 110, p. 303-309, jun. 2016 DOI: dx.doi.org/10.18671/scifor.v44n110.03 
